\title{
Managing cancer pain - Simple rules, major benefits
}

\author{
Dwight E Moulin MD FRCPC
}

$I^{\mathrm{n}}$ n the developed world, approximately one in three individuals will be diagnosed with cancer and one-half of those will die of progressive disease (1). At least $75 \%$ of patients with cancer develop pain before death. It is therefore not surprising that pain is one of the most feared consequences of cancer for both patients and families (2). The good news is that cancer pain can be controlled with relatively simple means in more than $80 \%$ of cases based on guidelines from the World Health Organization (3). Mild pain can be treated with acetaminophen or nonsteroidal anti-inflammatory drugs (Step 1 of the analgesic ladder). Moderate pain requires the addition of a 'minor' opioid such as codeine (Step 2), and severe pain mandates the use of a major opioid analgesic such as morphine (Step 3). In this issue of Pain Research $\mathcal{E}$ Management, Gallagher et al (pages 188-194) highlight some of the barriers to adequate cancer pain management based on a cross-sectional survey of British Columbian physicians. The survey response rate of $69 \%$ attests to the validity of their findings.

Gallagher et al found that there were major deficiencies in the knowledge of equianalgesic doses and adequate breakthrough dosing that is crucial in the provision of adequate cancer pain management. Two-thirds of surveyed physicians did not know that two tablets of Tylenol No 3 with Codeine (Janssen-Ortho/McNeil Consumer Healthcare, Canada) are approximately equal to $10 \mathrm{mg}$ of oral morphine. Almost onehalf did not know that the unit dose of opioid for breakthrough pain should be $10 \%$ of the total daily dose. These findings are consistent with previous surveys addressing the adequacy of cancer pain treatment. Cleeland et al (4), in their survey of 1308 outpatients with metastatic cancer, found that $42 \%$ of those with pain received inadequate analgesia. The majority of these patients had pain that was severe enough to impair function. These surveys reinforce the importance of being able to convert from Step 2 to Step 3 of the analgesic ladder. Tylenol No 3 with Codeine contains $30 \mathrm{mg}$ of codeine. The codeine alone in two tablets of Tylenol No 3 with Codeine is equivalent to $10 \mathrm{mg}$ of oral morphine (5). Patients who have inadequate pain relief on two tablets of Tylenol No 3 with Codeine every $4 \mathrm{~h}$ will require a minimum of immediate-release morphine $10 \mathrm{mg}$ every $4 \mathrm{~h}$ and perhaps double this dose. In terms of controlled-release morphine, the starting dose will be in the range of $30 \mathrm{mg}$ to $60 \mathrm{mg}$ twice daily or equivalent of another major opioid. Patients with severe and unrelieved chronic pain should have their total dose of morphine increased by $50 \%$ to $100 \%$ every $24 \mathrm{~h}$ to $48 \mathrm{~h} \mathrm{(5)}$ as long as side effects such as nausea and drowsiness are not dose limiting. This represents aggressive but appropriate opioid dose titration with a very low risk of respiratory depression or cardiovascular collapse (5). Similarly, opioid dosing for breakthrough pain needs to be aggressive because breakthrough pain is common in the setting of metastatic disease and is a major impediment to quality of life (6). The total daily dose of as-needed rescue medication can be as high as the regular dose (5). A unit dose of $10 \%$ of the total daily dose taken every $2 \mathrm{~h}$ to $3 \mathrm{~h}$ as needed (ie, up to 10 doses per day) will accomplish this.

Gallagher et al have identified major barriers to adequate cancer pain management based on the lack of knowledge of opioid dosing. Their findings in British Columbia can likely be extrapolated to the rest of the developed world. Palliative care teaching in most medical schools is woefully inadequate (7), and most medical textbooks carry very little information on the subject (8). Pain assessment and management including opioid dosing should be part of the core curriculum of all undergraduate and postgraduate training programs.

\section{REFERENCES}

1. World Health Organization. The World Health Report 1996 Fighting disease, fostering development. Executive Summary. Geneva, Switzerland: World Health Organization, 1996.

2. Foley KM. Controlling cancer pain. Hosp Pract (Off Ed) 2000;35:101-8,111-2.

3. Zech DF, Grond S, Lynch J, Hertel D, Lehmann KA. Validation of the World Health Organization guidelines for cancer pain relief: A 10-year prospective study. Pain 1995;63:65-76.

4. Cleeland CS, Gonin R, Hatfield AK, et al. Pain and its treatment in outpatients with metastatic cancer. N Engl J Med 1994;330:592-6.

5. Levy MH. Pharmacologic treatment of cancer pain. N Engl J Med 1996;335:1124-32.

6. Portenoy RK, Hagen NA. Breakthrough pain: Definition, prevalence and characteristics. Pain 1990;41:273-81.

7. Billings JA, Block S. Palliative care in undergraduate medical education: Status report and future directions. JAMA 1997;278:733-8.

8. Carron AT, Lynn J, Keaney P. End-of-life care in medical textbooks. Ann Intern Med 1999;130:82-6.

Departments of Oncology, London Regional Care Program and Clinical Neurological Sciences, London Health Sciences Centre, The University of Western Ontario, London, Ontario

Correspondence: Dr Dwight E Moulin, London Regional Cancer Centre, 790 Commissioners Road East, London, Ontario N6A 4L6.

Telephone 519-685-8661, fax 519-685-8636, e-mail dwight.moulin@lhsc.on.ca 


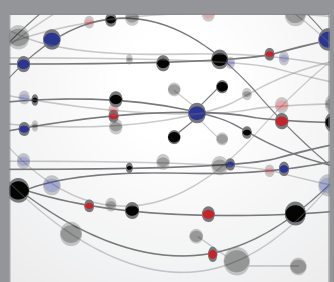

The Scientific World Journal
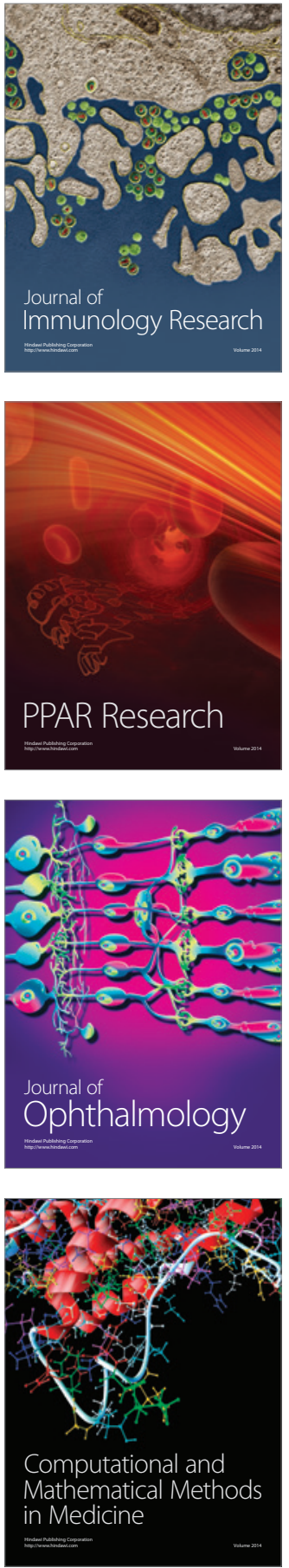

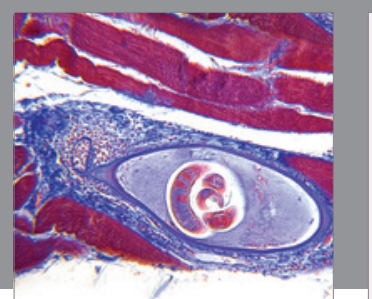

Gastroenterology Research and Practice

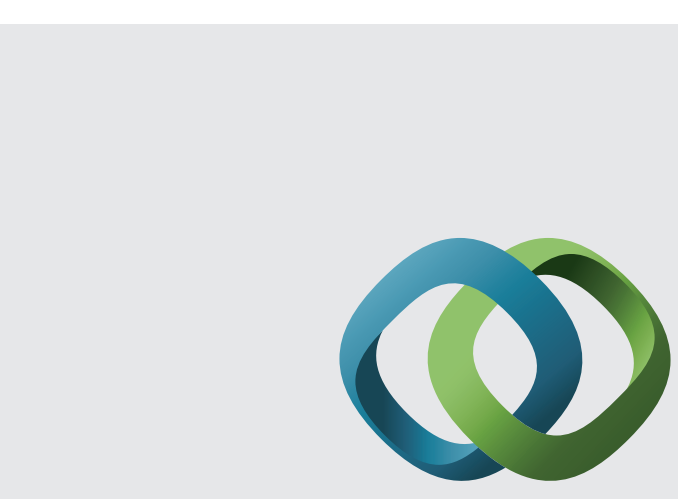

\section{Hindawi}

Submit your manuscripts at

http://www.hindawi.com
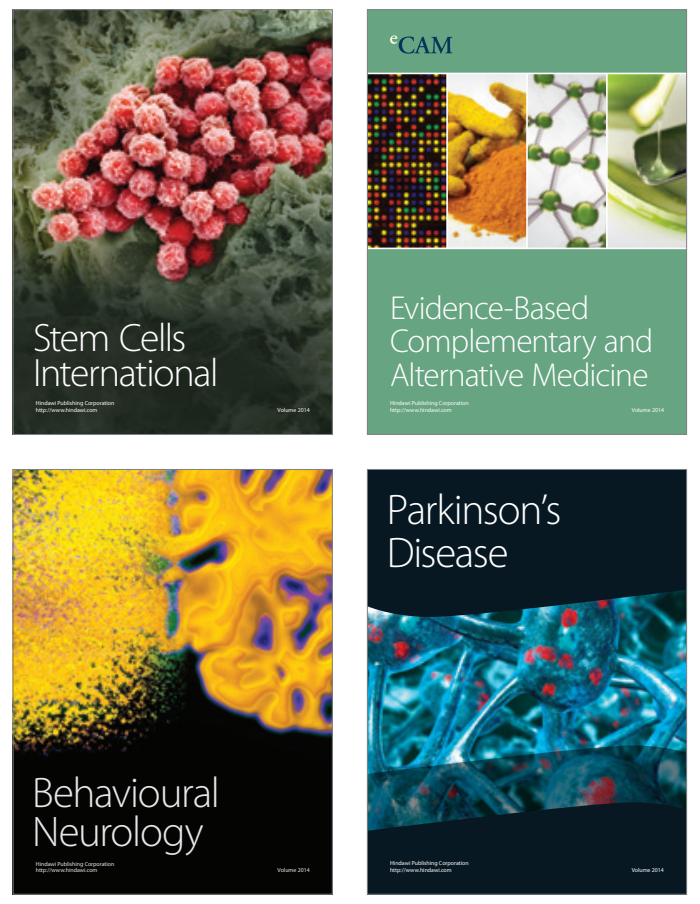
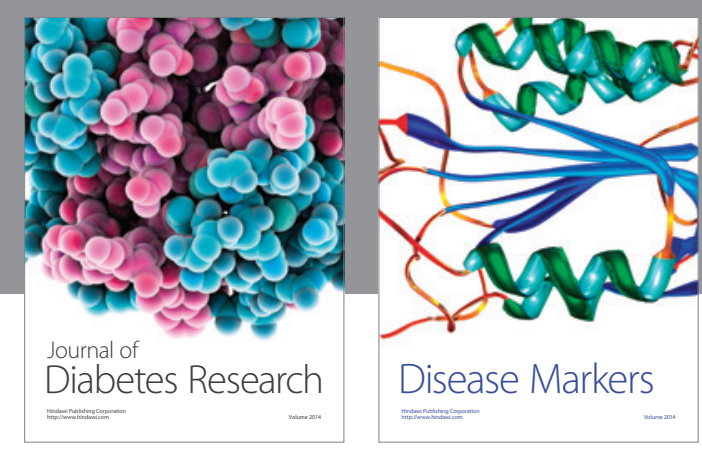

Disease Markers
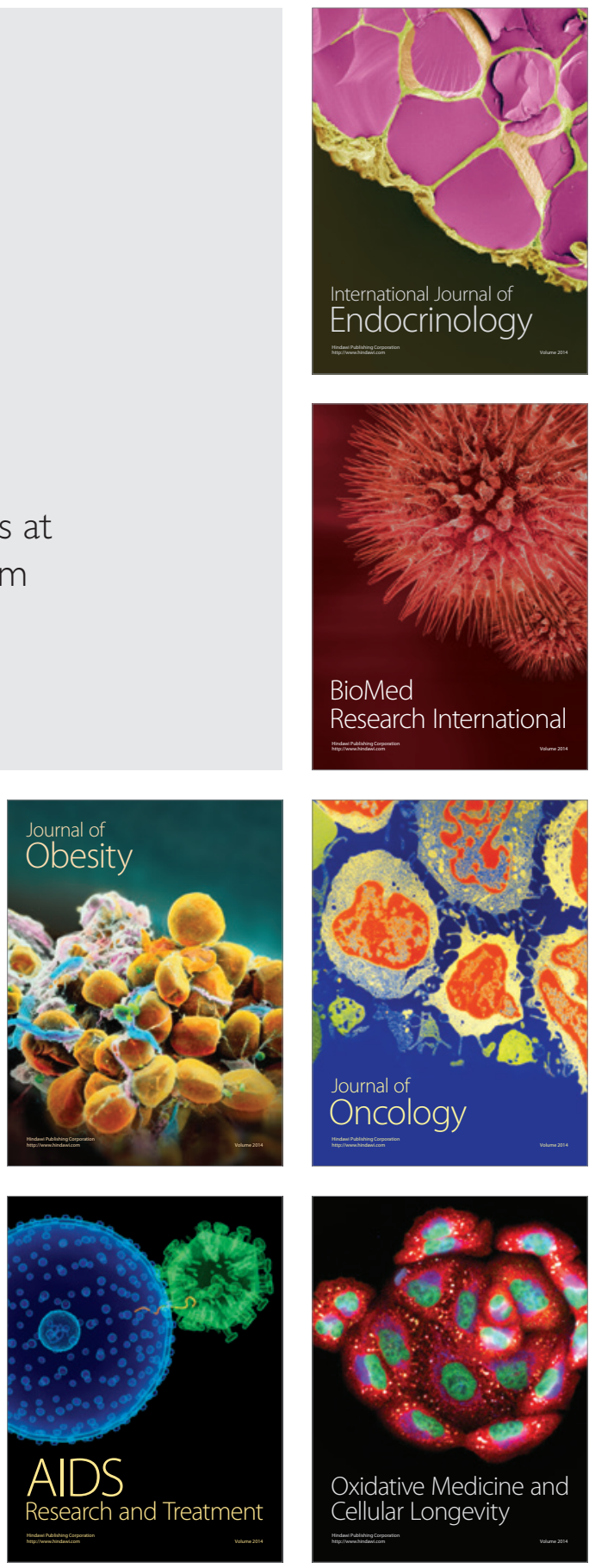